\title{
Practical Application of Contemporary Project Management SoftWare
}

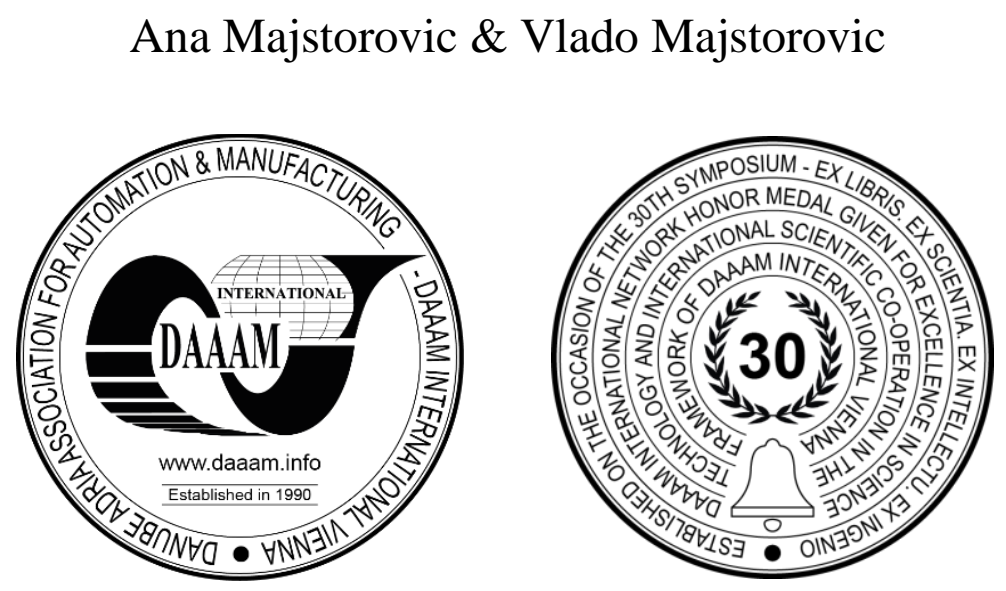

This Publication has to be referred as: Majstorovic, A[na] \& Majstorovic, V[lado] (2020). Practical Application of Contemporary Project Management Software, Proceedings of the 31st DAAAM International Symposium, pp.0851-0859, B. Katalinic (Ed.), Published by DAAAM International, ISBN 978-3-902734-29-7, ISSN 1726-9679, Vienna, Austria DOI: $10.2507 / 31$ st.daaam.proceedings.119

\begin{abstract}
The realization of modern business, activities and projects poses increasing demands and challenges to project managers. Therefore, modern project management practices are inconceivable without the help of project management software. This paper describes and compares the most commonly used project management software with emphasis on the need for careful selection based on the required software features and other criteria such as software price, necessary implementation time and education of future users and an example of Microsoft Project application in project planning.
\end{abstract}

Keywords: Project Management Software; Project Management; Planning Methods and Techniques; Microsoft Project.

\section{Introduction}

Due to the limited amount of resources necessary in any project, their optimal use is required in a way that reduces the total project duration and project costs, while achieving an improvement in the quality of the project result [8]. Contemporary business places increasing demands and challenges on the Project Manager, which creates an increasingly complex concept of project management. Therefore, we cannot think of project management today without the use of computer programmes. With the first application of such Project Management software computer systems required a great deal of user knowledge and were very slow. Development of personal computers contributed to the development of project management when they became more user-oriented and easily accessible to everyone.

To date, numerous software packages have been developed for Project Management and as such are an indispensable tool in planning activities, estimating project costs, resource management, reviewing a load of individual resources, monitoring project implementation and project control. It is important to keep in mind that a computer is a tool that cannot be planned independently without human commands, but a person with the help of a computer and computer software can do the routine part of the job much faster and more efficiently [9]. Using such software, instead of routine tasks in making the plan, the project team leaves more time for plan analysis, monitoring and control in the project implementation phase, which allows better decisions that ultimately affect the greater success of the project. However, in addition to all the listed benefits of implementing project management software, the question is also how to choose the software that will best suit the needs of the project team and that will help in successful project management. 
However, in addition to all the listed benefits of implementing project management software, the question is also how to choose the software that will best suit the needs of the project team and that will contribute to more successful project management. Through this paper, there will be given a brief overview of the development of project management software, analysis of some of the project management software and their proper selection and the application of Microsoft Project in project planning.

\section{Development of Project Management Software}

The emergence of project management software is often linked to the genesis and development of planning methods and techniques. One of the worthiest scientists in this field of science is considered to be Henry Gantt who presented the activities of the production process for the first time in real-time using a Gantt chart. Thus, the Gantt chart has remained one of the most applied methods in project planning to this day. Gantt chart is one of the linear planning methods and is most often used in combination with some of the network planning techniques that emerged a little later, with the advent of more complex projects. The PERT method was used for the planning and control of the US Navy Polaris project [4]. As this project was unique and the duration could not be precisely determined, its estimates based on optimistic, most probable, and pessimistic time were used. The final execution time of the project activities was obtained by mathematical beta distribution as the expected duration of the activities [6].

Initially, the PERT method did not take costs into account until the introduction of the PERT / COST method in which project cost estimation was done by the same logic as time estimation in the PERT method. Unlike the Polaris project, the construction of a large chemical plant in the United States for which EI du Pont de Nemours was responsible required an accurate estimate of the time and cost of the project. For this purpose, a planning method was developed primarily referred to as the PPS, and today better is known as the CPM method. The CPM method is still used today in the planning of projects in which the execution of activities can be precisely determined. It is event-oriented and uses time analysis and structure analysis to accurately determine the duration of activities, the occurrence of events, and the total duration of the project [5]. With the development of planning methods and techniques there was a need for another method called the method of previous activities or PDM method.This method was developed in response to the shortcomings of the PERT and CPM methods in which it was not possible to display two activities taking place simultaneously. The PDM method introduced different types of temporal relationships between activities making the actual relations between activities better represented than before [9]. With the development of computers and the application of the first packages intended for project management, these techniques and methods of project planning, on which this computer software is based, gained popularity.

\section{Review and selection of the project management software}

Today, there is a large number of project management software solutions on the market, and this paper provides its readers with an overview and analysis of Asana, Trello, Microsoft Project, Basecamp and Wrike project management software. Asana is a project management solution that enables collaboration and communication among project team members. It is a simple implementation tool, has an attractive user interface, and access to this tool is enabled through the mobile application that offers a possibility of synchronizing the user account on the desktop and mobile version of the programme.

Trello is one of the most attractive project management software programmes on the market due to its ease of use, relatively affordable price and great collaboration opportunities among project team members. The most common use of this tool is in simple projects managed by a small project team. One of the major advantages of this programme is the ability to use it on a whole range of devices from a desktop computer, laptop or tablet as well as a mobile phone using a mobile app available for both iOS and Android devices.

Microsoft Project is also a commonly used project management software in practice. It is present due to the integration with Office 365, but it also offers many features and customization options at the enterprise level. It is most commonly used to manage complex projects involving a large number of stakeholders. In its newer versions, it also features agile methodologies to be able to compete with new software programmes in the market such as Asana, Trello, Basecamp, Wrike, etc. Basecamp is a project management tool used by all types of teams, from small and medium to large companies. It is easy to use, has several features such as project planning, real-time project monitoring, the ability to collaborate among project team members, the ability to work on multiple projects simultaneously, etc. Basecamp can integrate with Trello and Asana project management software. Wrike is a cloud-based project management tool that helps users manage a project from start to finish, providing complete visibility and control over tasks, and it is implemented both in large and medium-sized enterprises. Although at first glance quite similar, each of the analyzed project management computer programmes has its advantages and disadvantages and several features and capabilities for project management. It is necessary to understand the needs and the problem that we believe the implementation of one of these software programmes could solve to understand which set of features would best suit us. The software that contains such a set of features is the best solution for the project team. Therefore, in the continuation of this paper, a comparison of the analyzed project management software is given according to the possession of eight key features necessary for successful project management, namely project planning, real-time_project presentation, project milestones, multi-project capability, resource management, collaboration, monitoring project progress. 


\begin{tabular}{|c|l|l|l|l|l|}
\hline $\begin{array}{c}\text { Features of Project } \\
\text { Management Software }\end{array}$ & Asana & Trello & $\begin{array}{c}\text { Microsoft } \\
\text { Project }\end{array}$ & Basecamp & Wrike \\
\hline Project Planning & & & & & \\
\hline Project Time Tracking & & & & & \\
\hline Milestones Tracking & & & & \\
\hline Multiple Projects & & & & \\
\hline Resource Management & & & & & \\
\hline Collaboration Tools & & & & \\
\hline Progress Tracking & & & & \\
\hline Reports and Statistics & & & & \\
\hline
\end{tabular}

Table 1. Comparison of project management software features (Source: by the author)

For the purposes of correct selection of project management software the previously presented features of project management software were defined as criteria and the analysed software as possible alternatives on the basis of which a hierarchical AHP model was created in the computer program Expert Choice (Figure 1.)[2].

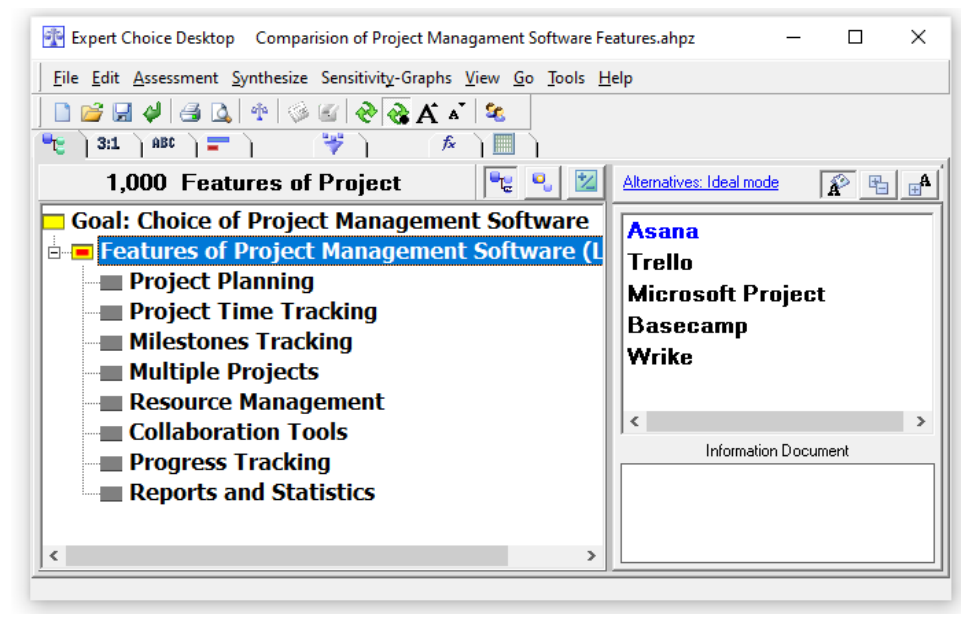

Fig. 1. AHP model

After defining the hierarchical AHP model, the evaluation of alternative software was performed according to the criteria of owning the selected features. Sensitivity analysis ranked Asana as the best software solution, followed by Microsoft Project, Wrike, Basecamp and finally Trello (Figure 2).

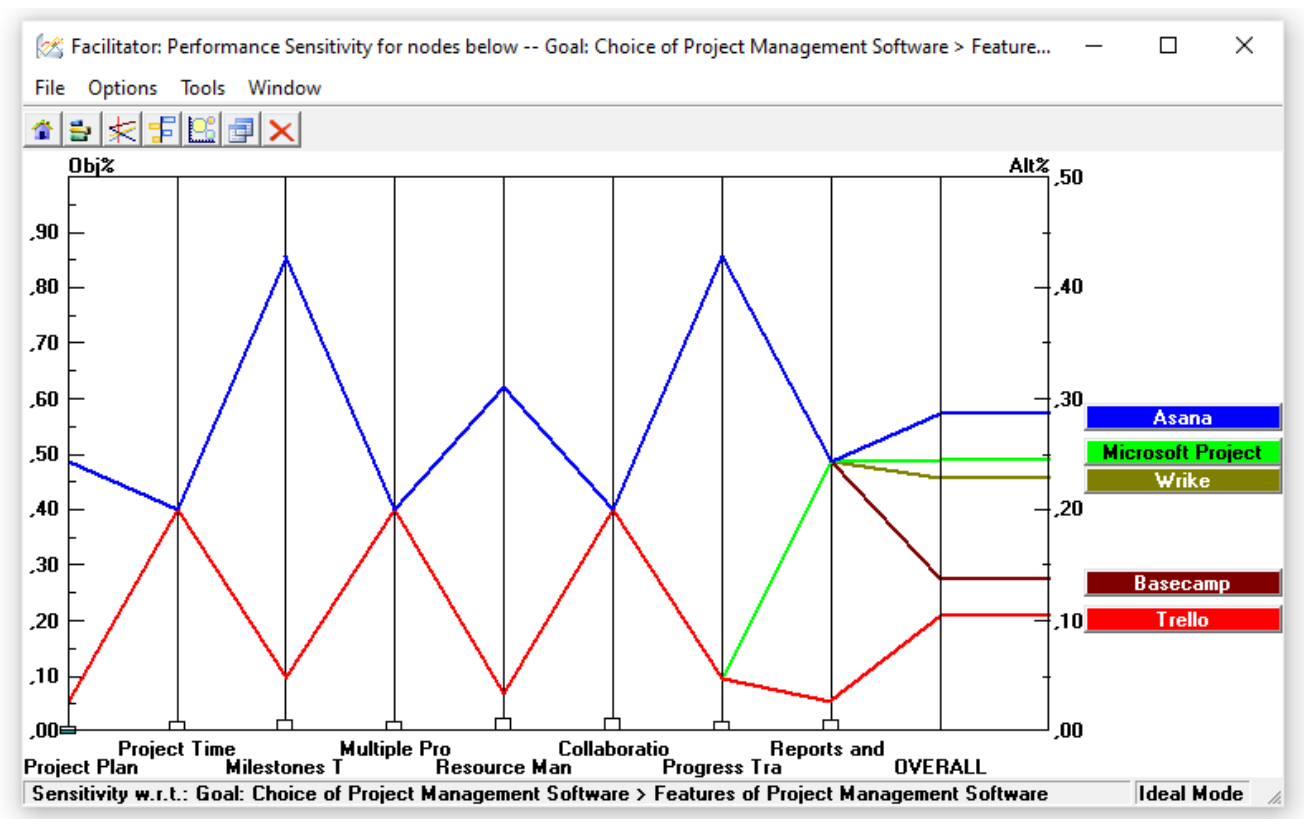

Fig. 2. Evaluation results of analysed software 
In addition to choosing the best software solution regarding the features that will help manage a particular project, it is important to pay attention to the following three limitations, namely the price of software, time of its implementation and education and use of selected software programme [7]. Before deciding to purchase project management software, it is very important to determine how much money we are willing to spend, whether that amount is in line with the organization's capabilities, and whether the price of the software will justify the benefit we will receive from it. Besides the fee for the use of the software, it is necessary to take into account the implementation and education costs, and the adaptation to the purchased software. It is important to consider the needs and opinions of all project participants and future users to facilitate the implementation of the selected software programme. It will reduce possible resistance when using the software, and its use will make it easier for everyone to work and thus improve the project management process. After selecting and implementing the software and before using it, it is necessary to educate future users so that they learn to use the system correctly and get to know all its features and characteristics for which the software was selected. The following is a description of the MS Project and its application in planning.

\section{Application of Microsoft Project in project planning}

Project is used in planning and managing a large number of different projects, from meeting deadlines and budgets to choosing the right resources. MS Project is mostly applied in practice today, and the reason for that is its simplicity, availability and reasonable price, and by using all its possibilities, higher productivity and better results are achieved. This software is applicable in almost all branches of industry, especially in the field of construction. As such, it is most often implemented in design and construction companies that participate in the execution and monitoring and control of project implementation. Microsoft Project is available in two different versions, Project Standard and Project Professional. The first version allows you to create, modify and track plans, while the second also has additional features such as Team Planner. Also, Project Professional can be used with Project Server and Project Online, which in addition to project management also enables portfolio management. Then, portfolio management enables monitoring of all projects that the company is engaged in, optimization of resources its resources and control of all activities and costs with one tool [1].

Microsoft Project has a series of features and capabilities for more successful project management so in this paper will be shown on the example of construction project some of previously analysed features such as project planning and project time tracking which includes entering activities and their duration, grouping activities into a WBS structure; linking activities with appropriate links; then allocation and managing the resources needed to execution of these activities; creating different reports and statistics and the ability of collaboration between stakeholders involved in the project.

\subsection{Project planning and time tracking}

The feature of project planning and time tracking in Microsoft Project will be presented on the example of the construction of a business-residential building laid on a reinforced concrete foundation slab $40 \mathrm{~cm}$ thick in its total area of $164 \mathrm{~m} 2$. The construction extends to 4 floors, including the basement, ground floor, first and second floor.

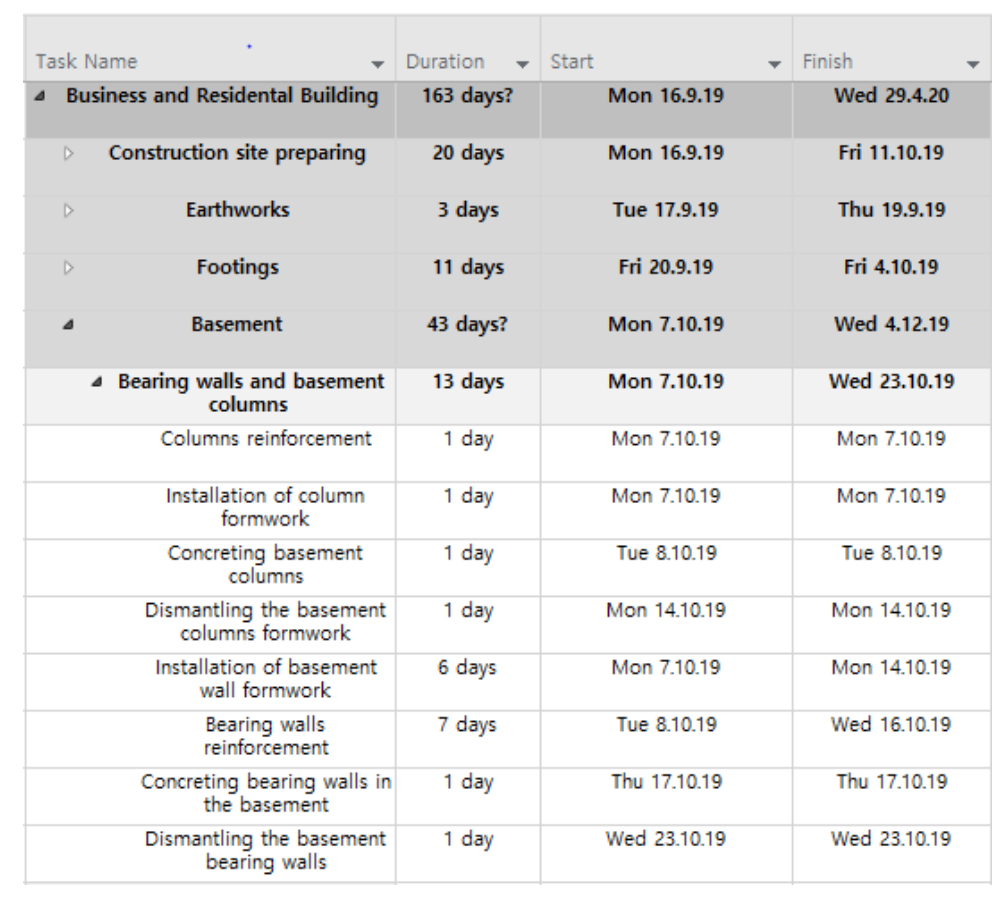

Fig. 3. Work Breakdown Structure - WBS (Source: by the author) 
The load-bearing structure consists of reinforced concrete elements of concrete class $\mathrm{C} 25 / 30$. The construction ends with a flat roof $25 \mathrm{~cm}$ thick made of reinforced concrete C25/30. The agreed start date of works is on September 16, 2019, while the planned completion of works is on April 29, 2020. After the survey of the works, a WBS structure was created by which this project is presented through components in developed and connected levels, from the whole to the details, which are necessary for the implementation of effective planning, monitoring and control. The disaggregated structure of the paper is shown from top to bottom in four levels of detail (Figure 3.).

After entering all the selected activities that need to be performed for this project, it is necessary to determine the duration of individual activities and determine the links between the activities. By entering the specified data in the tabular part of the basic window, MS Project calculates the exact start and end date of each activity, the critical project path and the total project duration following the agreed completion time [1].

Figure 4. shows the basic plan for the construction of a business-residential building using a Gantt chart. The welldesigned initial plan includes entering quality input information results. With the development of the initial plan, this part of the work is just beginning as well as monitoring and control of the plan to determine whether the plan follows the actual situation on the construction site, and if not it is necessary to update it at any time to show the real project.

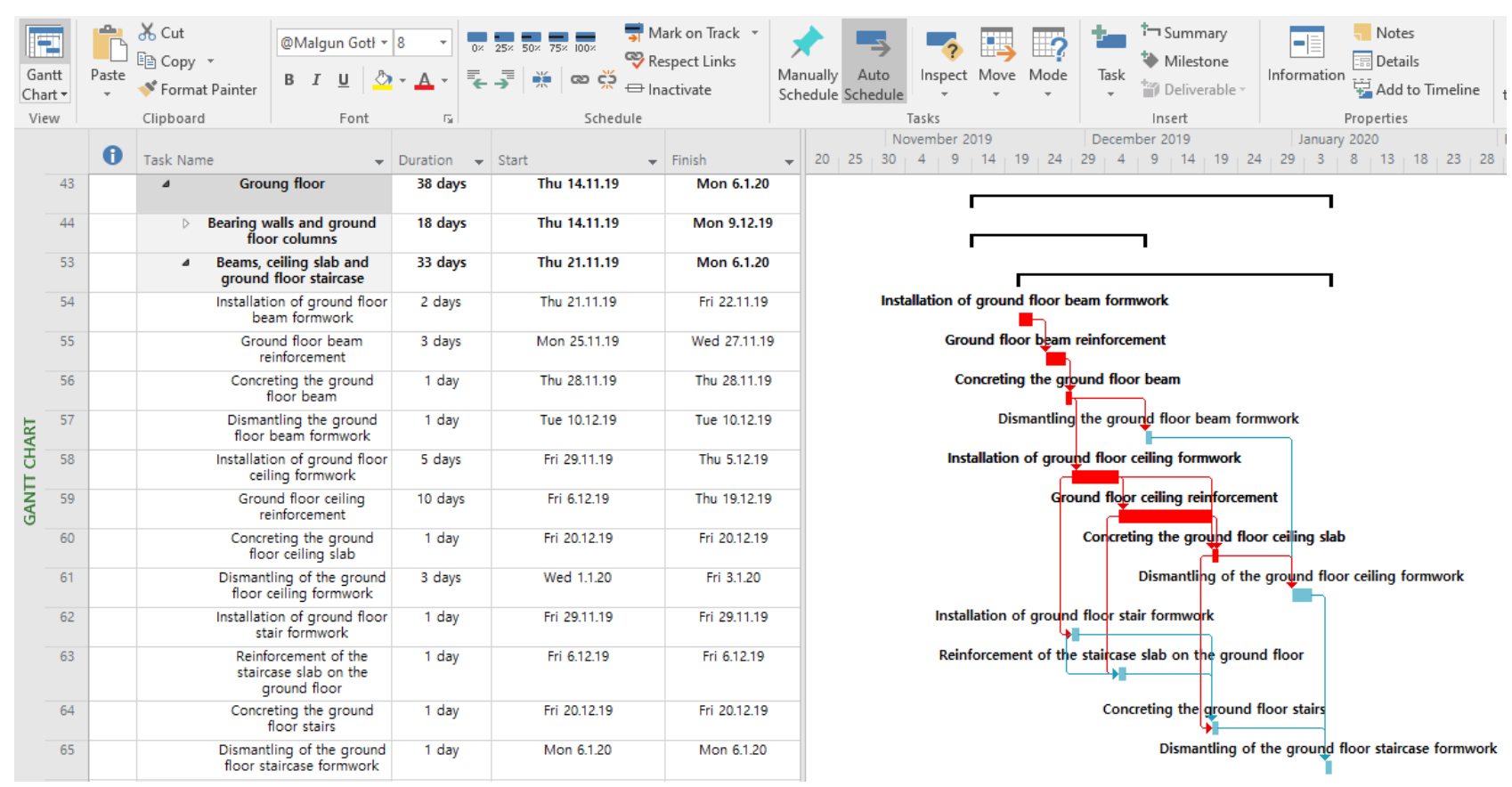

Fig. 4. Display of the basic plan in MS Project (Source: by the author)

In the basis of MS Project, the calculation is performed following the method of previous activities, and it is possible to display the plan in the form of a network diagram at any time.

\section{Comparison of activity duration calculations classical and with the help of project management software}

The Critical Path Method - CPM and Precedence Diagramming Method - PDM are the most commonly used methods in planning construction projects today and represent the concept on which most software programmes are based on planning and creating a project plan [10].The following is an example of calculating the duration of the part of the activities in the plan and comparing the obtained data with the data generated from Microsoft Project 2016.

\section{Classical method}

According to the PDM method, it is necessary to perform structural analysis and time analysis to determine the critical path and the total duration of the project. The analysis of the structure consists of the selection of activities and determining the connections between them. Its visual presentation is given by a network diagram for which the input data are shown in Table 2. When using the elements for drawing a network diagram, it is necessary to link the activities from the first to the last in the list of activities, paying attention to their interdependence 


\begin{tabular}{|c|c|c|c|}
\hline $\begin{array}{c}\text { Label of } \\
\text { the } \\
\text { activity }\end{array}$ & \multicolumn{1}{c|}{ Task Name } & Duration & $\begin{array}{c}\text { Previous } \\
\text { activity }\end{array}$ \\
\hline A & Reinforcement of basement columns & 1 & - \\
\hline B & Installation of basement column formwork & 1 & 1 SS \\
\hline C & Concreting basement columns & 1 & 1,2 \\
\hline D & Dismantling the basement column formwork & 1 & 3 FS+3 \\
\hline E & Installation of formwork for load-bearing basement walls & 6 & $2 S S$ \\
\hline F & Reinforcement of load-bearing basement walls & 7 & $5 \mathrm{SS}$ \\
\hline G & Concreting the load-bearing walls of the basement & 1 & 5,6 \\
\hline H & Dismantling of load-bearing basement-walls & 1 & $7 \mathrm{FS}+3,4$ \\
\hline
\end{tabular}

Table 2. List of the activities (Source: the author of the paper)

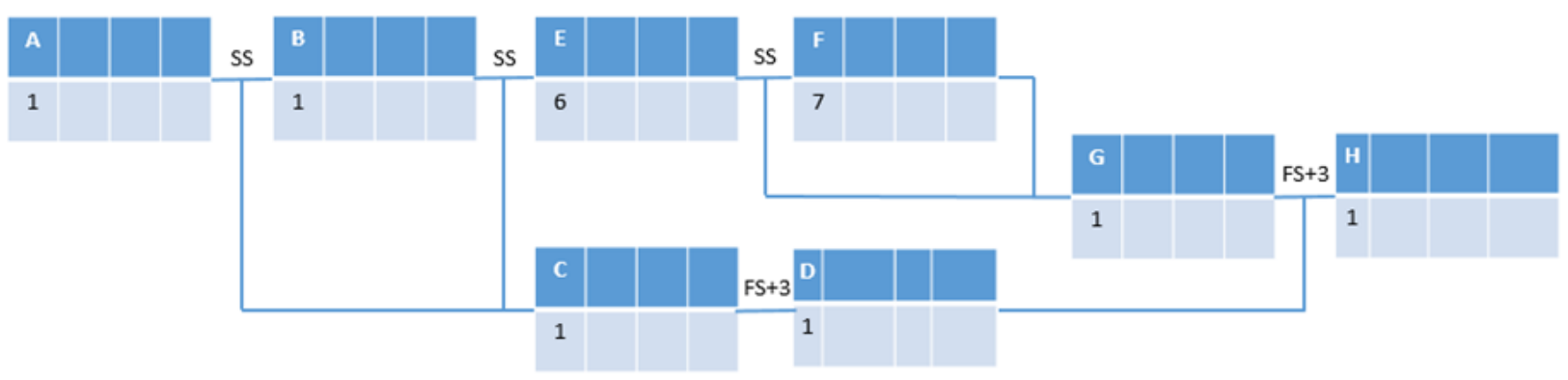

Fig. 5. Structure analysis (Source: by the author)

After analysing the structure, it is necessary to determine the time schedule for the execution of individual activities and the total duration of the project. In the network diagram, according to the rules of the PDM method, it is necessary to perform an advance calculation that determines the working position of the activity and a backward calculation that determines the latest activity position. In addition to budgeting forward and backwards, it is necessary to calculate time reserves in order to get a critical path and critical activities, i.e. those activities that do not have time reserves and extending their duration extends the total duration of the entire project.

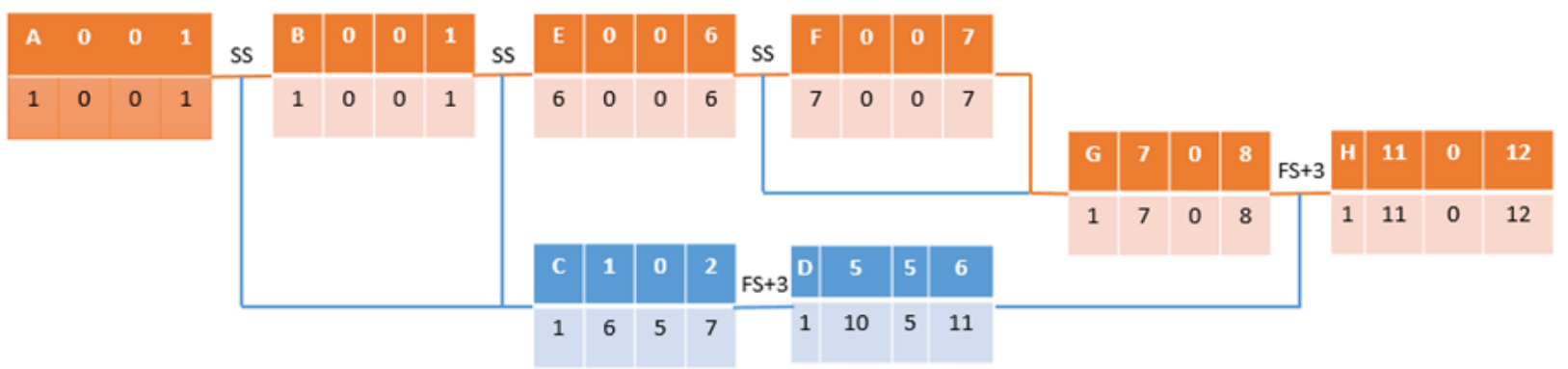

Fig. 6. Time Analysis (Source: the author of the paper)

\section{Planning in MS Project}

The budget procedure described above is automatically implemented by the software in its background. Entering the name of the activity in the Task Name column, the duration of individual activities in the Duration column and previous activities in the Previous Activities Column on the right side of the main window draws a Gantt chart. The critical activities are marked in red and non-critical ones in blue. It can be noticed that the obtained data coincide with those data obtained by manual calculation. 


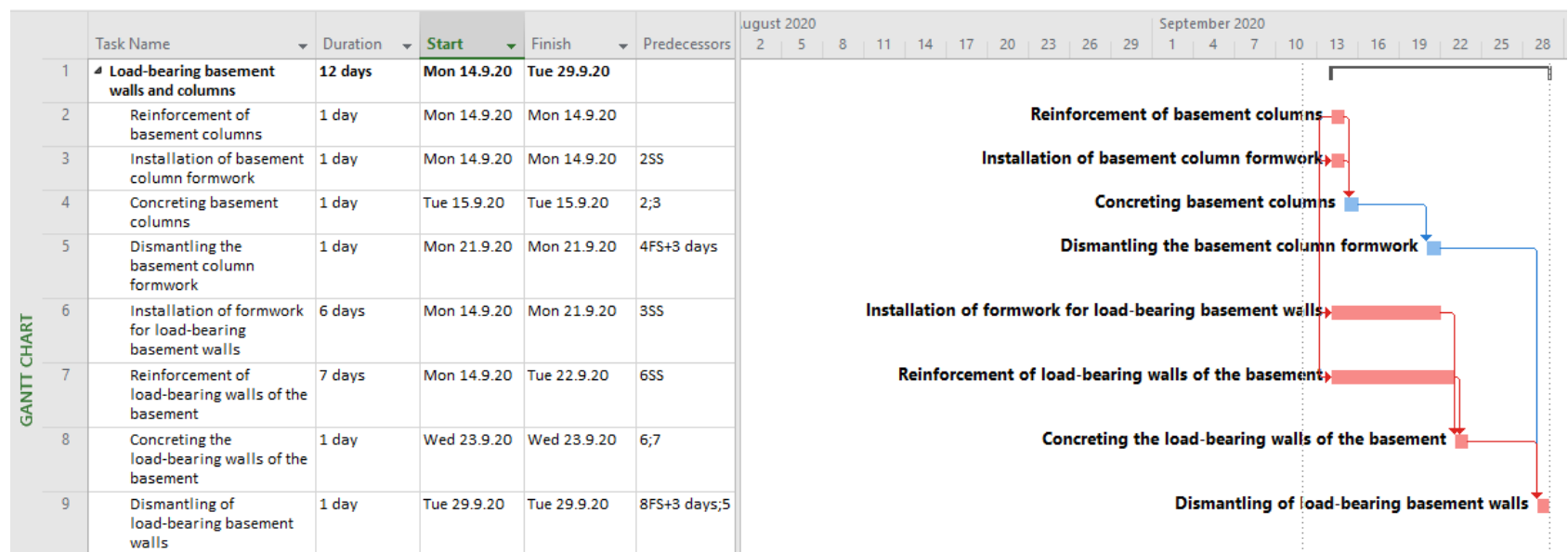

Fig. 7. List of the activities and Gantt Chart (Source: by the author)

Figure 5 shows a network diagram of the construction of columns and load-bearing walls of the basement in which a complete coincidence can be seen with the hand-drawn and calculated network diagram shown in Figures 2 and 3.

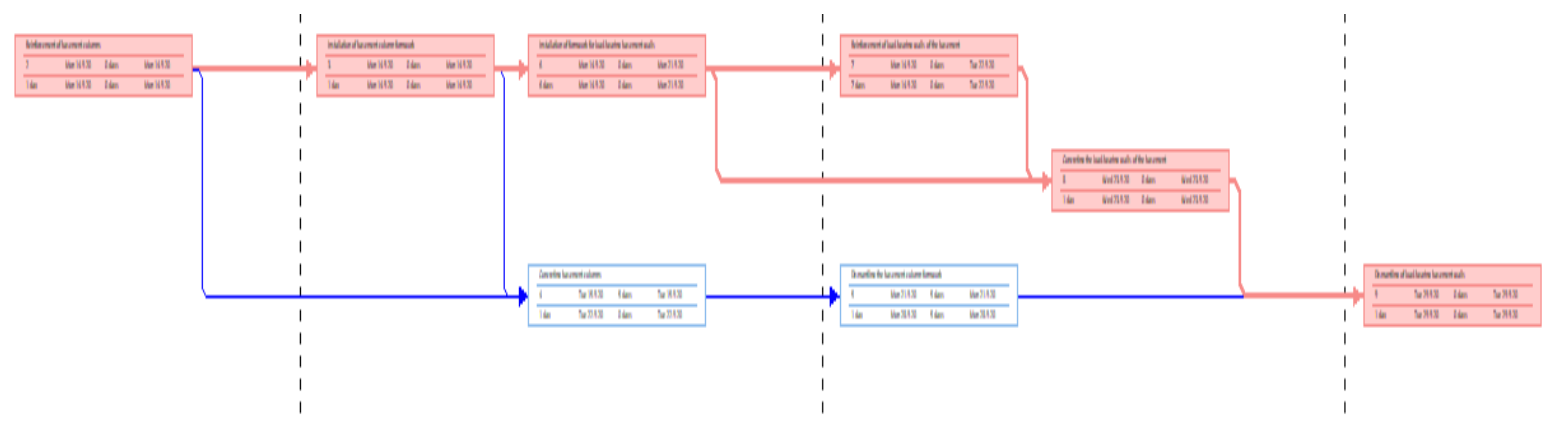

Fig. 8. Network Diagram (Source: by the author)

A simple example with a few activities as possible is presented here. However, it is impossible to manually plan projects with a large number of activities and a large number of resources required for their implementation, such as a single construction project without the use of the software. It is possible to create a project plan, but during the implementation of the construction, a large number of participants is involved. Therefore, constant changes have to be continuously updated in the plan, and this requires a large amount of time that the project team often does not have.

\subsection{Project Resource Management}

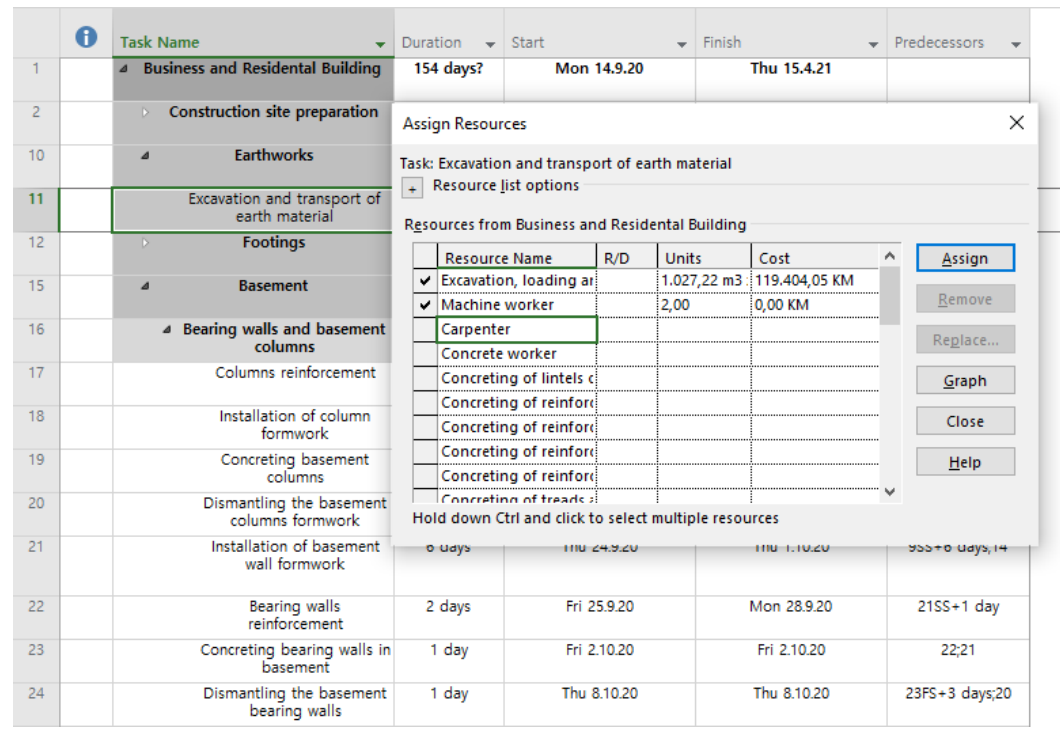

Fig. 9. Assignment resources to activities 
The work planned in the project can only be done with the help of resources. Efficient resource management is one of the biggest advantages of using Microsoft Project. The successful realisation of the project depends on the availability of human and material resources at the right time and in the required amount [3]. The allocation of activity resources is necessary for its execution which gives a schedule for the using resources that can be optimized later. By entering data on resources such as the name and type of resources, the unit of measure and the limited number available, a database is created where all available project resources are located in one place. In order to obtain a real-time resource allocation on the project, it is necessary to assign to each activity the type and amount of resources needed to execution that activity (Figure 9).

When all the activities in the plan have been allocated the necessary resources, Microsoft Project creates a histogram of the resources whose horizontal axis shows the time, and the vertical axis the number of resources that are planned and monitored over time (Figure 10).

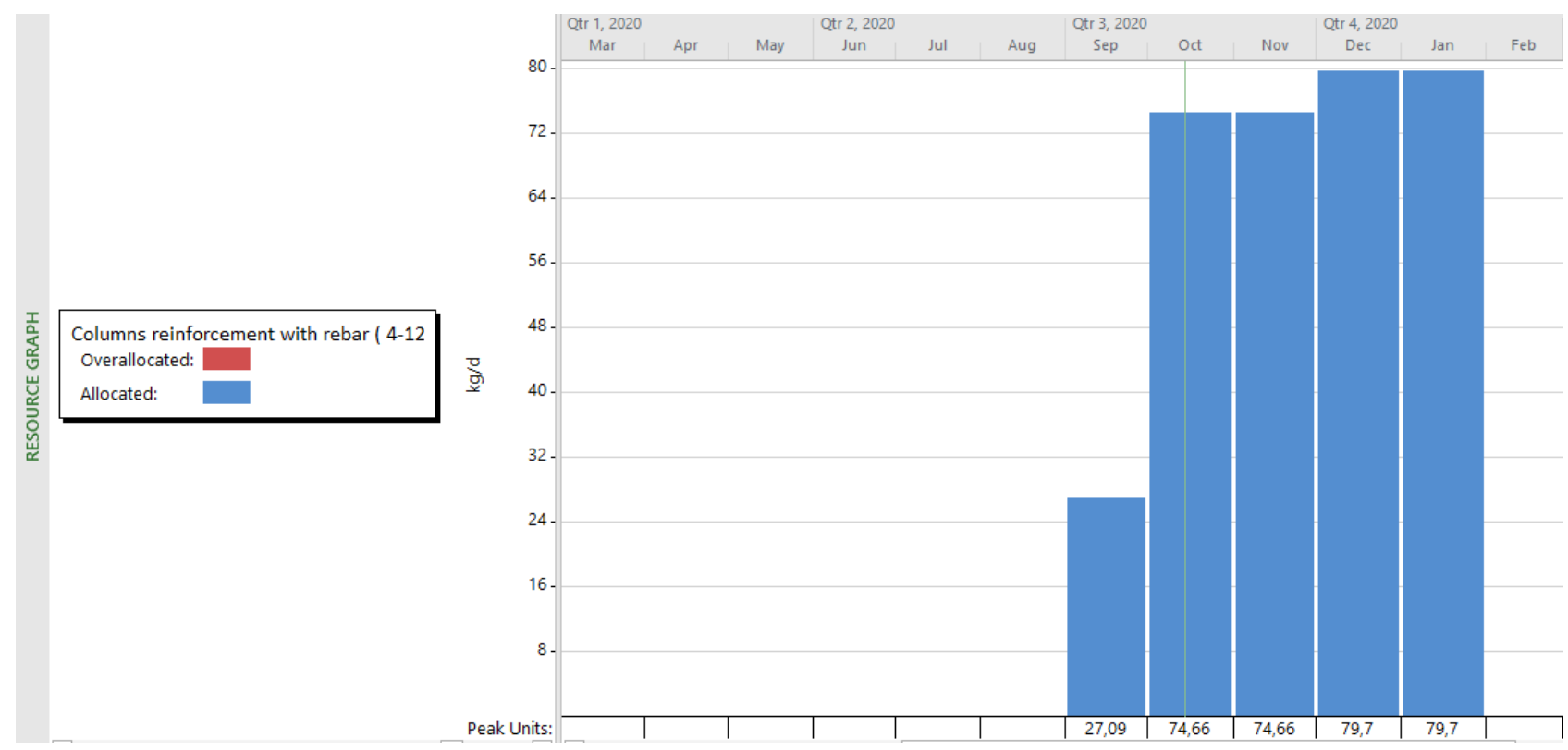

Fig. 10. Histogram of resource

\subsection{Reporting and statistics}

This project management tool as another of its features offers different reports that provide insight into all the necessary information about the current state of the project. It is possible to get an insight into the cash flow on the project, a work overview, a view of the schedule of resources as resource overview, milestones report and many other reports. Figure 11. shows a report that provides an insight into the state of human resources engaged in the project. Project reporting provides visibility and support in making a decision that represents a proactive approach to project management.
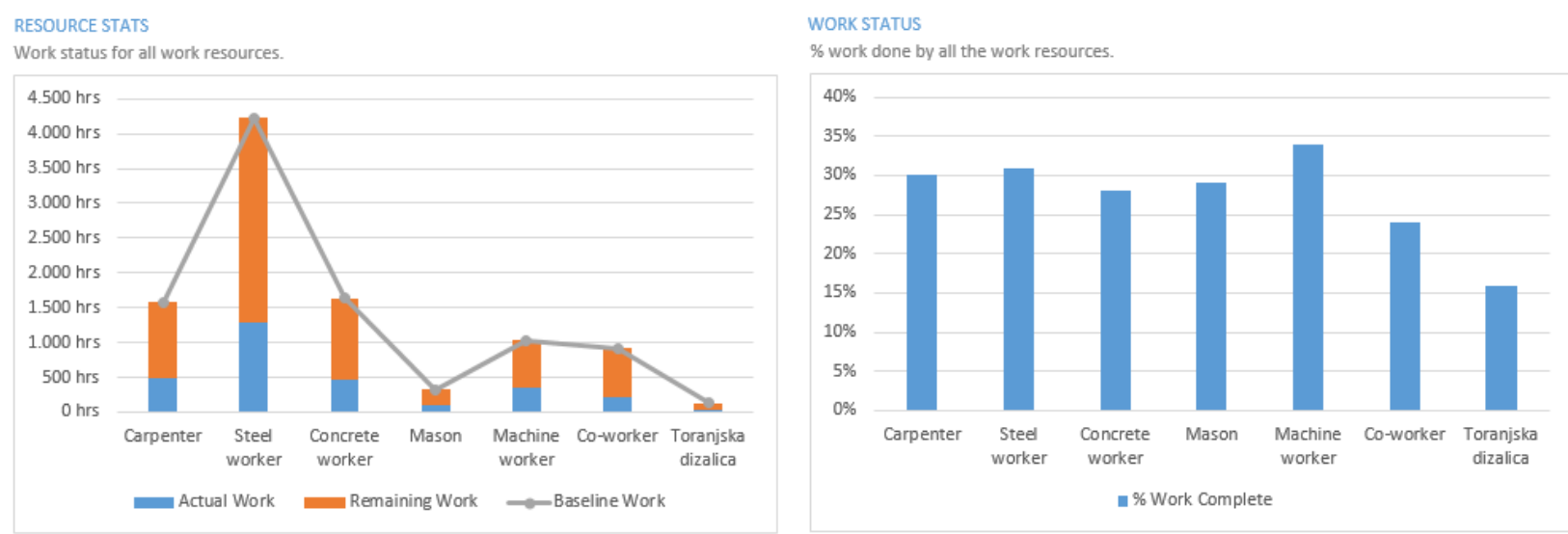

Fig. 11. Resource status report 


\subsection{Collaboration in Microsoft Project}

An integral part of the Microsoft Project Professional version is collaboration between project team members using synchronization between MS Project and SharePoint. Each member of the project team accesses SharePoint, updates the status of the project and by synchronizing these two tools, the changes become visible to all other members of the project team [1].

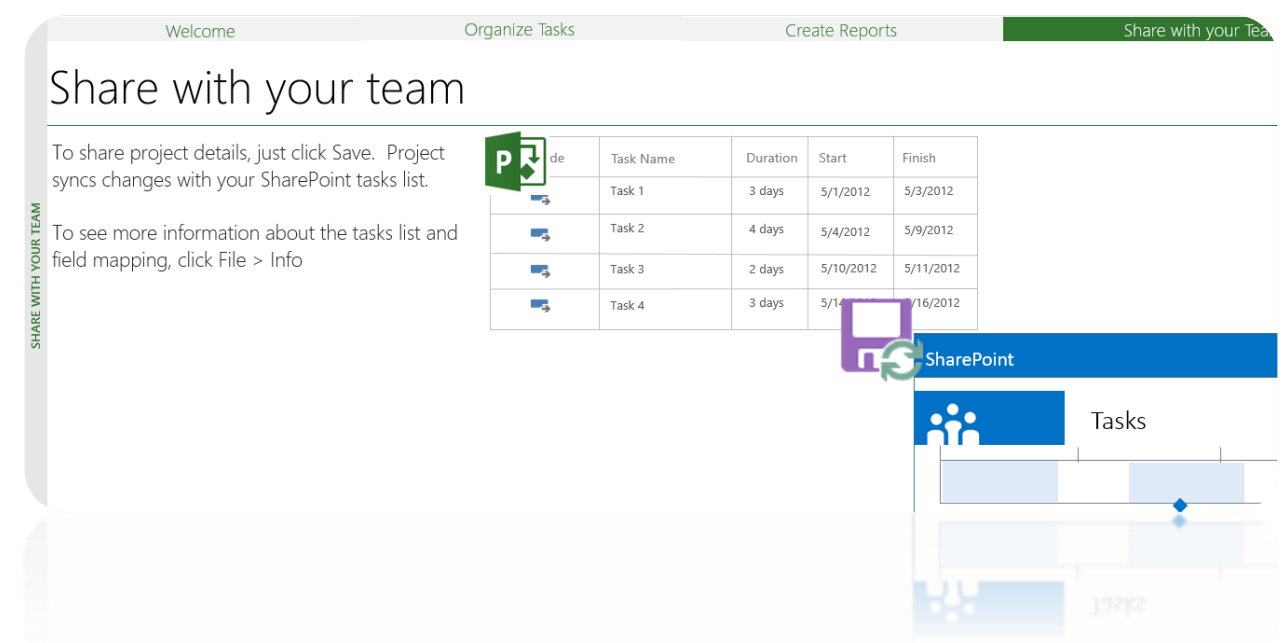

Fig. 12. Synchronization with SharePoint

\section{Conclusion}

Intensive development of project management and expansion of its field of application requires the help of modern project management software. The paper gives a brief description and comparison of the most commonly used project management software programmes and answers the question of how to choose the software that can support project management. It also gives an overview of the application of Microsoft Project in planning a specific project in construction. Finally, the conclusion is that project management software should be selected based on the required features. In addition to a set of features that will help more successful management of a project when choosing it, it is necessary to take into account the software costs, the required implementation time and education of stakeholders who will use it. By the application of modern project management software, the project team has more time for plan analysis, monitoring and control of project execution, which allows better decisions for the better success of the project.

In the future, project management will become unthinkable without the support of project management software, so investing in new technologies and monitoring the development of project management software will be a challenge in achieving sustainable competitive advantage.

\section{References}

[1] Chatfield, C. \& Johnson, T.(2017). Microsoft Project 2016 Step by Step, First Edition, Microsoft Press

[2] Erdogan, S. A.; Saparauskas, J. \& Turskis, Z. (2017). Decision Making in Construction Management: AHP and Expert Choice Approach, Available from: https://www.sciencedirect.com/science/article/pii/S1877705817306173 Accessed: 2020-09-10

[3] Heldman, W.(2004). IT Project + Study Guide, 2nd Edition Sybex Inc

[4] Kundu, J.; Bishoi, T. K.; Bhattacharya, M. \& Chowdhury,A.(2015). Project Management Software - An Overview, International Journal of Current Innovation Research, Vol. 1, Issue 6, pp 129-135.

[5] Majstorovic, V.(2010), Project Management, University of Mostar, Mostar

[6] Majstorovic V.; Bandić, Glavaš M. \& Milinković, Rosić I.(2009). Statistical Background for Development Pert Project Management Technique Software Tool, The 20th DAAAM International Symposium Intelligent Manufacturing \& Automation: Theory, Practice \& Education, Vienna, Austria

[7] Omazic, M. A. \& Baljkas, S.(2005). Project Management, Sinergija nakladništvo d.o.o., Zagreb

[8] Project Management Institute - PMI(2017). A guide to the Project Management Body of Knowledge, PMBOK Guide, 6th edition

[9] Radujkovic, M. et al.(2015). Planning and Control of Projects, Faculty of Civil Engineering, University of Zagreb, Zagreb

[10] Suci ,M.\& Sugarindra, M.(2019). Utilizing project management software in project scheduling: a case Study, IOP Conference Series: Materials Science and Engineering 